\title{
INVESTIGATING ENVIRONMENTAL CONCERNS FOR PRIMARY SCHOOL TEACHERS
}

\author{
Siti Patonah, Sentot Budi Rahardjo, Cari, Sajidan \\ Universitas Sebelas Maret \\ sitipatonahs3@student.uns.ac.id
}

\section{Article History}

accepted 30/09/2018

approved $12 / 10 / 2018$

published 30/10/2018

\section{Keywords}

Investigating,

environmental

concerns, primary school

teachers

\begin{abstract}
The success of environmental education in schools is largely determined by the teacher's factors at school. The purpose of this research is to get the teacher's view of the environmental concern. This research method is a cross sectional survey. The survey was conducted randomly to 950 elementary school teachers who were scattered in two locations of the PLPG program in Central Java in 2017. Obtained 148 samples from 10 regencies and cities in 1 rayon and 1 sub rayon. The results obtained indicate that the knowledge of elementary school teachers' environment is in good condition even though it has not directly influenced attitudes, or habits.
\end{abstract}

Social, Humanities, and Education Studies (SHEs): Conference Series

p-ISSN 2620-9284 https://jurnal.uns.ac.id/shes 


\section{PENDAHULUAN}

Permasalahan kerusakan lingkungan akhir-akhir ini santer dibicarakan. Diantara sekian penyebab kerusakan lingkungan adalah aktivitas manusia, yang dikenal sebagai faktor antropogenik. Namun demikian, selain sebagai penyebab manusia juga sekaligus sumber solusi yang dapat diandalkan (Mei, Wai, \& Ahamad, 2016). Oleh karenanya berbagai upaya dilakukan oleh manusia atau untuk manusia dalam rangka memperbaiki kelestarian lingkungan.

Melalui pendidikan, pemahaman individu terhadap potensi lingkungan hidup dan upaya menjaga kelestariannya diharapkan dapat berhasil. Keberhasilan dalam pendidikan lingkungan hidup membawa dampak positif bagi lingkungan. Pemahaman seseorang mengenai lingkungan hidup mendorong seseorang untuk memiliki kepedulian lingkungan sehingga mempengaruhi seseorang untuk tertarik pada hal-hal yang berhubungan dengan lingkungan serta tercermin dalam sikap dan perilakunya sehari-hari (Karahan \& Roehrig, 2015)

Berkaitan dengan proses pendidikan, guru mempunyai peran yang strategis dalam menentukan arah pembaharuan di bidang lingkungan hidup. Guru merupakan ujung tombak keberhasilan suatu bangsa atau kehancuran suatu bangsa. Pendidikan yang diberikan kepada seseorang sejak usia dini berpengaruh pada kehidupannya di masa kini maupun masa depan, bahkan sepanjang hidupnya. Proses kepedulian lingkungan diyakini sebagai proses yang dapat difasilitasi melalui proses pembelajaran, karena proses hasil pendidikan tidak dapat diamati hanya dalam beberapa bulan (Ardoin, Biedenweg, \& O'Connor, 2015). Oleh karena itu mengetahui sejauh mana persepsi guru berkaitan dengan pengetahuan, sikap, kesadaran, dan perilaku guru terhadap masalah lingkungan menjadi hal yang utama sebelum melakukan upaya pemberdayaannya. Pengetahuan guru terhadap hal yang berkaitan dengan lingkungan hidup mempengaruhi kepeduliannya terhadap lingkungan. Pihak ecosentris menyebutkan bahwa kerusakan lingkungan efek dari aktivitas manusia, terdapat hubungan timbal balik antara manusia dengan lingkungan. Di pihak lain, kelompok. Kerusakan alam yang semakin meningkat diprediksi kuat karena adanya perilaku manusia terhadap lingkungannya. Perilaku ini berkaitan dengan pengetahuan seseorang (Carmi, Arnon, \& Orion, 2015). Kepedulian lingkungan meliputi 3 dimensi yaitu kognitif, afektif, dan konaktif (Bouscasse, Joly, \& Bonnel, 2018; Helm, Pollitt, Barnett, Curran, \& Craig, 2018; Kokkinen, 2013). Kognitif merupakan sekumpulan informasi yang tersimpan dalam memory otak, dari kumpulan kognitif ini kemudian tercermin dalam sikap yang dimunculkan yang pada akhirnya akan mengarah pada tindakan nyata. Tujuan dari penelitian ini adalah untuk menganalisis persepsi guru sekolah dasar terhadap masalah lingkungan

\section{METODE}

Metode penelitian ini merupakan metode penelitian surveytipe cross sectional.

\section{Subjek penelitian}

Penelitian ini merupakan penelitian survey dengan tipe cross sectional. Survey dilakukan kepada guru-guru yang mengikuti program PLPG tahun 2017 yang berasal dari Rayon dan Rayon 139. Sebanyak 148 sample diambil dari 950 populasi yang tersebar di 10 kabupaten dan kota di wilayah kedua rayon di Jawa Tengah. Sebanyak 200 angket yang diberikan yang kembali sejumlah 148 buah.

\section{Instrumen penelitian}

Instrumen penelitian yang digunakana adalah instrumen penelitian kepedulian lingkungan sekitar yang dikembangkan oleh Wai,2016 dari malaysia dengan melakukan adaptasi seizin dari penyusunnya. Instrumen terdiri dari 5 komponen 
berkaitan dengan kepedulian lingkungan, pengetahuan lingkungan, sikap terhadap lingkungan, ketertarikan terhadap lingkungan dan perilaku terhadap lingkungan. Selain itu juga terdapat komponen demografi yang meliputi jenis kelamin, pengalaman mengajar, jarak rumah dengan tempat mengajar, gaji bulanan, transportasi yang digunakan, dan administrasi tentang sampah. Keseluruan butir angket berjumlah 60 .

\section{Demografi peserta}

\section{HASIL DAN PEMBAHASAN}

Demografi peserta ditunjukkan dalam Tabel 1. Berdasarkan Tabel 1, jumlah guru SD didominasi oleh guru-guru wanita $(70,3 \%)$, pengalaman mengajar secara umum adalah pada 6-10 tahun (73,6\%). Gaji bulanan dominan 1-3 juta setiap bulannya $(23 \%)$. Jarak dari rumah ke tempat mengajar sebagian besar $(43,2 \%)$ berjarak lebih dari $6 \mathrm{~km}$. Jenis transportasi yang digunakan pada umumnya menggunakan sepeda motor $(91,2 \%)$. Di masing-masing sekolah sudah terdapat tempat sampah terpilah $52,7 \%$. Keberadaan bank sampah di sekolah belum optimal. Baru $37,2 \%$.

Tabel 1. Demografi Responden

\begin{tabular}{|c|c|c|c|}
\hline \multirow[t]{2}{*}{ Jenis kelamin } & $\mathrm{L}$ & 44 & 29,7 \\
\hline & $\mathrm{P}$ & 104 & 70,3 \\
\hline \multirow[t]{6}{*}{ Pengamalan mengajar } & $<5$ tahun & 22 & 14,9 \\
\hline & 6-10 tahun & 109 & 73,6 \\
\hline & 11-15 tahun & 13 & 8,8 \\
\hline & 16-20 tahun & 1 & 0,7 \\
\hline & $20-25$ tahun & 1 & 0,7 \\
\hline & $>25$ tahun & 3 & 2,0 \\
\hline \multirow[t]{3}{*}{ Gaji bulanan } & $<1$ juta & 6 & 4,1 \\
\hline & $1-3 \mathrm{jt}$ & 105 & 70,9 \\
\hline & $>3 \mathrm{jt}$ & 34 & 23,0 \\
\hline \multirow[t]{10}{*}{ Asal Daerah } & Rembang & 26 & 17,6 \\
\hline & Demak & 20 & 13,5 \\
\hline & Pati & 32 & 21,6 \\
\hline & Banjarnegara & 7 & 4,7 \\
\hline & Boyolali & 11 & 7,4 \\
\hline & Surakarta & 14 & 9,5 \\
\hline & Temanggung & 7 & 4,7 \\
\hline & Grobogan & 4 & 2,7 \\
\hline & Wonosobo & 9 & 6,1 \\
\hline & Purbalingga & 3 & 2,0 \\
\hline \multirow[t]{6}{*}{ Asal PT } & UT & 56 & 37,8 \\
\hline & UNNES & 10 & 6,8 \\
\hline & PGSD & 40 & 27,0 \\
\hline & UMS & 5 & 3,4 \\
\hline & UNY & 1 & 0,7 \\
\hline & P.ekonomi & 1 & 0,7 \\
\hline \multirow[t]{6}{*}{ Transportasi yang digunakan } & Jalan kaki & 3 & 2,0 \\
\hline & Mobil & 1 & 0,7 \\
\hline & Sepeda motor & 135 & 91,2 \\
\hline & Sepeda & 2 & 1,4 \\
\hline & Bis/ angkot & 4 & 2,7 \\
\hline & Mix & 0 & 0,0 \\
\hline \multirow[t]{3}{*}{ Jarak rumah ke sekolah } & $<1 \mathrm{~km}$ & 7 & 4,7 \\
\hline & $1,1-3 \mathrm{~km}$ & 32 & 21,6 \\
\hline & $3,1-6 \mathrm{~km}$ & 27 & 18,2 \\
\hline
\end{tabular}


SHEs: Conference Series 1 (2) (2018) 416-423

\begin{tabular}{llll}
\hline \multirow{3}{*}{ Fasilitas tempat sampah terpilah } & $>6 \mathrm{~km}$ & 64 & 43,2 \\
& Terdapat & 78 & 52,7 \\
& Tidak terdapat & 68 & 45,9 \\
Fasilitas bank sampah & Terdapat & 55 & 37,2 \\
& Tidak terdapat & 92 & 62,2 \\
\hline
\end{tabular}

\section{Trend Kepedulian Guru SD}

\section{Kepedulian lingkungan}

Pada point ini item terdiri dari 10 butir dengan skala likert 1-4, dimana 1 sangat tidak setuju dan 4 sangat setuju. Jawaban guru atas angket ini ditunjukkan pada Grafik 1.

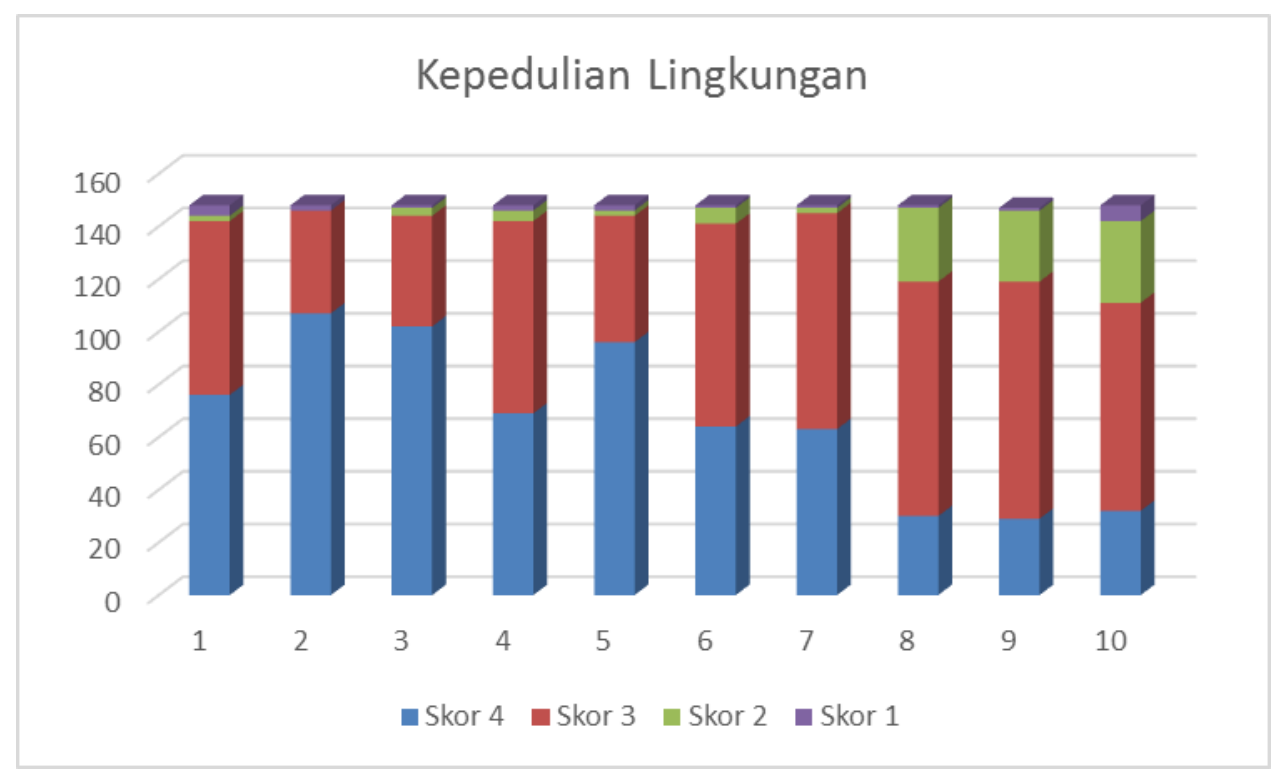

Grafik 1. Trend Kepedulian Lingkungan

Skor 4 terbesar (setuju) ada pada point 2 "air limbah yang tidak diolah dapat menurunkan kualitas lingkungan". Sedangkan skor 4 terkecil ada pada point 9 "Cuaca ekstrim adalah hasil dari aktivitas manusia".

\section{Environmental knowledge}

Pengetahuan mengenai lingkungan terdapat 10 butir dengan skala Likert 1-4. Hasil respon peserta pada angket ini ditunjukkan pada Grafik 2. 
SHEs: Conference Series 1 (2) (2018) 416-423

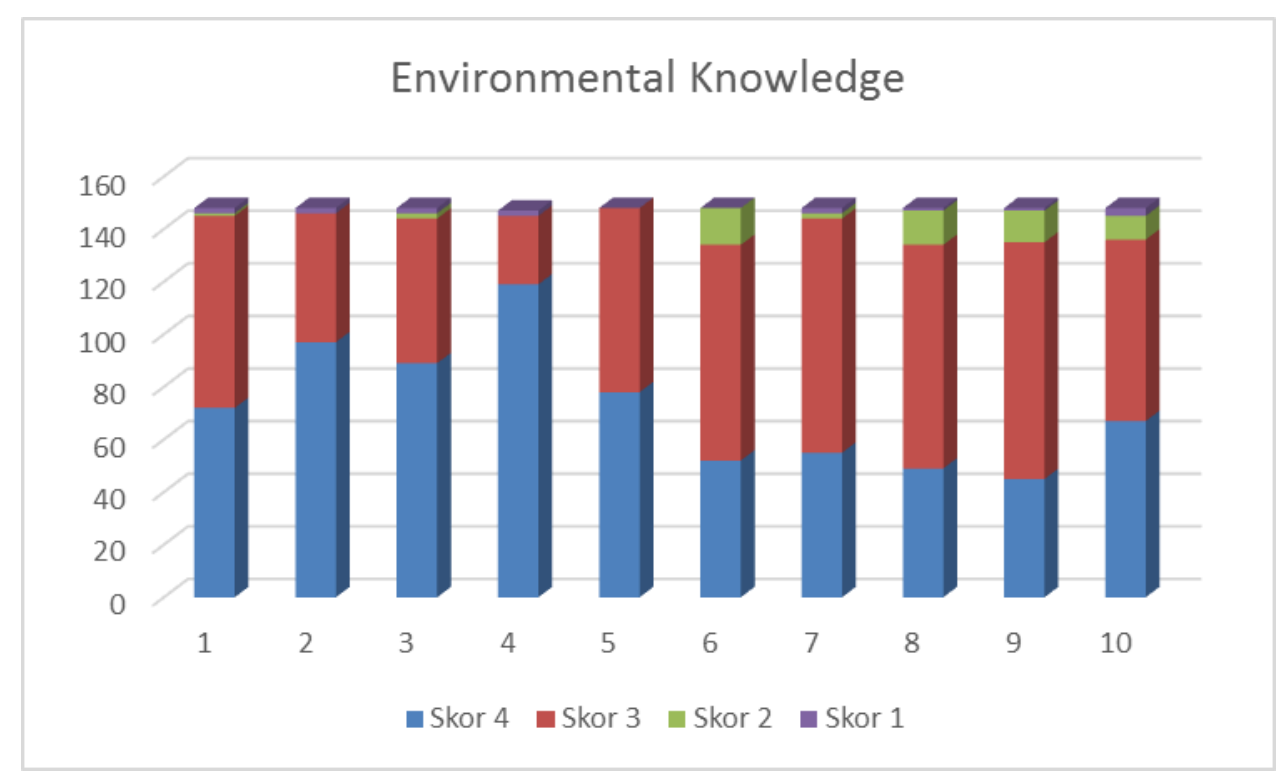

\section{Grafik 2. Tingkat Pengetahuan Guru pada Lingkungan}

Untuk pengetahuan yang paling tinggi tentang lingkungan ada pada point 4 "Kebiasaan menggunakan air dan listrik seperlunya dapat menghemat biaya'. Sedangkan yang paling rendah ada pada 9, "Service mobil/ motor secara berkala dapat memaksimalkan kecukupan penggunaan bahan bakar".

\section{Environmental Behavior}

Dalam sub ini, terdapat 25 butir item dengan skala 1-4 untuk menyatakan 'Tidak pernah' untuk 1, jarang untuk 2, selalu untuk 3, dan sering untuk 4. Hasil dari domain ini ditunjukkan pada Grafik 3.

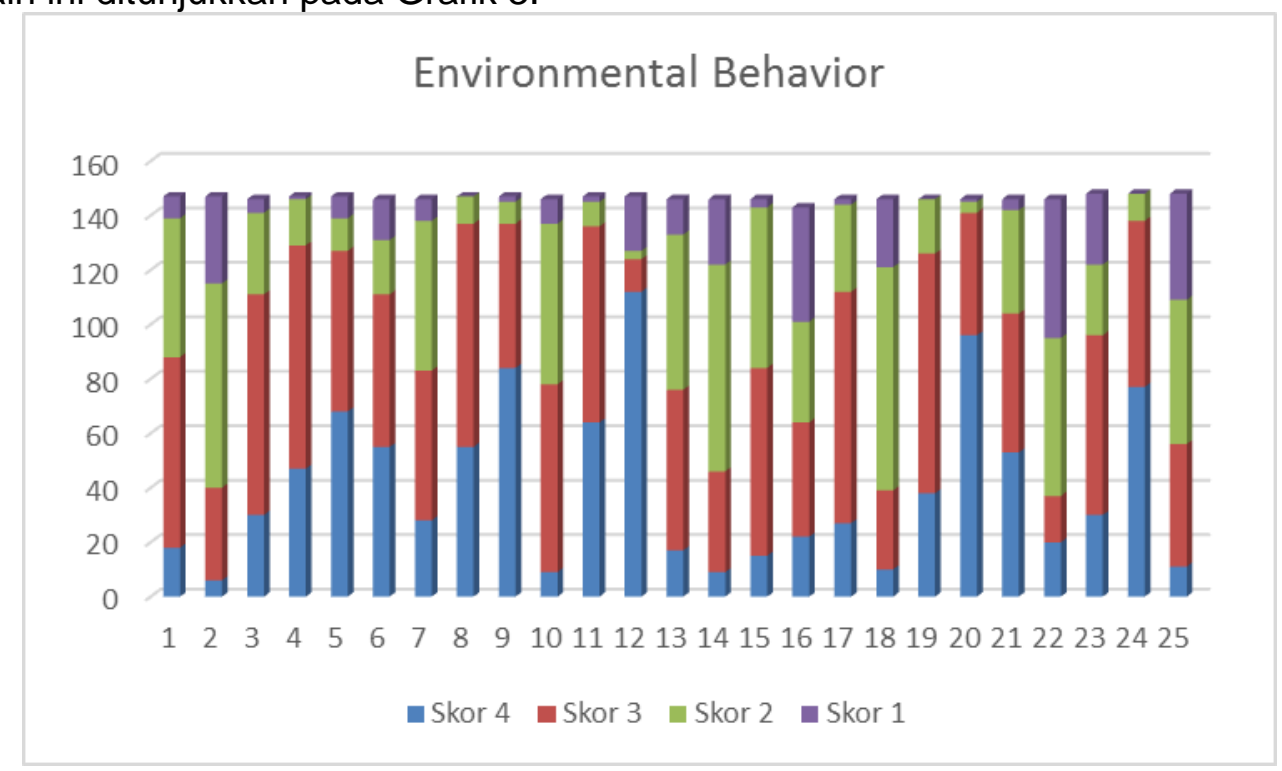

\section{Grafik 3. Tingkat Environmental behavior}

Point 12 "saya tidak merokok", merupakan pilihan setuju paling tinggi. Hal ini dimungkinkan karena responden $70 \%$ adalah perempuan. Sangat tidak setuju yang terbesar adalah "saya menanam pohon". 


\section{Environmental Concern}

Point ini terdapat 12 item yang terbagi dalam 2 komponen. Dimana untuk item 1-5 skala likert yang digunakan adalah 1-4 dengan untuk 1: sangat tidak rela, 2: tidak rela, 3: agak rela, dan 4: sangat rela. Untuk item 6-12 menggunakan skla likert 1-4 untuk sangat tidak setuju-sangat setuju. Grafik 4 menunjukkan respon ketertarikan guru terhadap permasalahan lingkungan.

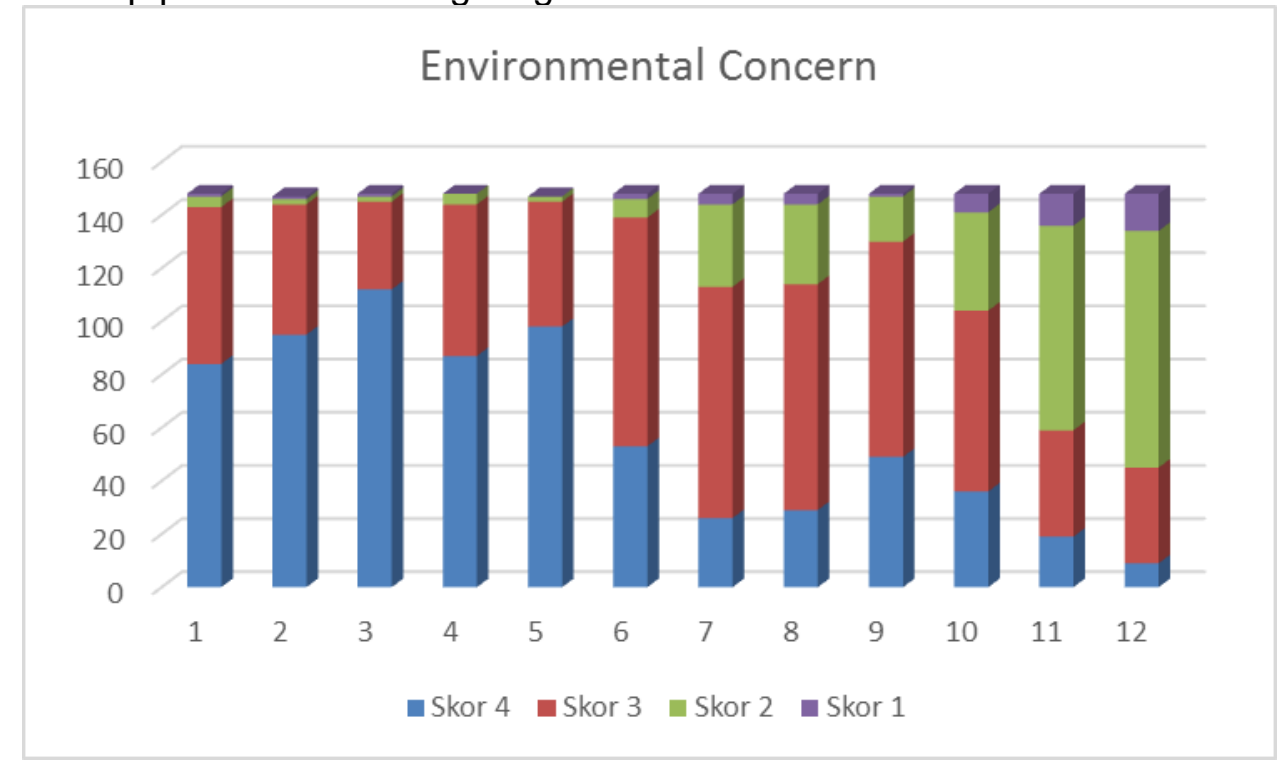

\section{Grafik 4. Tingkat kepedulian lingkungan}

Responden sangat bersedia untuk point 3 "Bersedia mengurangi standar hidup (misal: hemat energi, hemat air) untuk melindungi lingkungan". Mereka paling setuju untuk point "IImu pengetahuan modern akan memecahkan masalah lingkungan kita dengan sedikit perubahan pada cara hidup kita".

\section{Environmental Attitude}

Untuk sub environmental attitude. Skala likert yang digunakan 1-4 dengan 1 sangat tidak setuju dan 4 sangat setuju. Hasil dari respon guru terhadap item environmental awareness ditunjukkan pada Grafik 5.

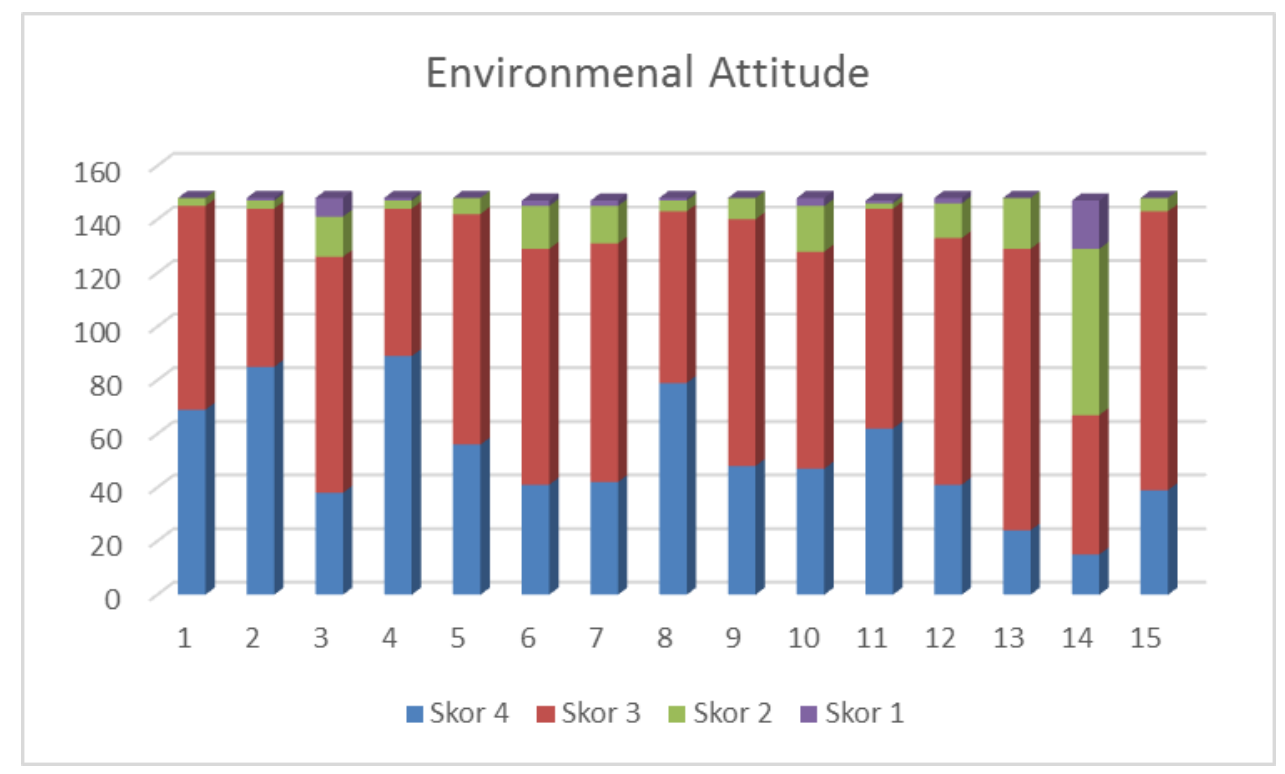


Untuk hal yang mereka sangat disetujui ada pada point 4 "Tumbuhan dan hewan mempunyai hak yang sama dengan manusia untuk hidup".

Dengan menggunakan SPSS, korelasi antar variabel ditunjukkan pada Tabel 2.

Tabel 2. Hasil SPSS untuk korelasi antar variabel

\begin{tabular}{rrrrrr}
\multicolumn{4}{c}{ Model Summary } \\
\hline Model & R & R Square & \multicolumn{1}{c}{ Sqdjusted R } & \multicolumn{1}{c}{$\begin{array}{c}\text { Std. Error of } \\
\text { the Estimate }\end{array}$} \\
\hline 1 &, $632^{\mathrm{a}}$ &, 399 &, 382 & 2,99552 \\
\hline
\end{tabular}

a. Predictors: (Constant), E.Attitude, E.Awareness, E.Concern,

E.Bihaviour

Dari Tabel 2, menunjukkan adanya korelasi antara pengetahuan lingkungan terhadap kepedulian, ketertarikan, sikap, dan perilaku terhadap lingkungan. Pengaruhnya sebesar $63,20 \%$.

Sedangkan pengetahuan lingkungan mempengaruhi kepedulian lingkungan, sikap terhadap lingkungan, ketertarikan pada lingkungan dan perilaku terhadap lingkungan. Hal ini ditunjukkan pada Tabel 3.

Tabel 3. Hasil SPSS untuk pengaruh masing-masing variabel

\begin{tabular}{llrrrrr}
\hline Model & & Sum of Squares & df & Mean Square & F & Sig. \\
\hline 1 & Regression & 852,162 & 4 & 213,040 & 23,742 &, $000^{b}$ \\
& Residual & 1283,156 & 143 & 8,973 & & \\
& Total & 2135,318 & 147 & & & \\
\hline
\end{tabular}

a. Dependent Variable: E.Knowledge

b. Predictors: (Constant), E.Attitude, E.Awareness, E.Concern, E.Bihaviour

Besarnya $F$ tabel dengan derajat kebebasan (3;147) diperoleh sebesar 2,60 sedangkan $F$ hitung sebesar 23,742. Karena $F$ tabel $<F$ hitung maka dapat disimpulkan bahwa seluruh variabel independent berpengaruh terhadap variabel dependent dan sebaliknya.

Untuk mengetahui besarnya pengaruh variabel terikat dari masing-masing variabel bebas ditunjukkan pada Tabel 4. 
Tabel 4. Besarnya pengaruh masing-masing variabel

Coefficients $^{\mathrm{a}}$

\begin{tabular}{|c|c|c|c|c|c|c|c|c|}
\hline & \multirow[b]{2}{*}{ Model } & \multicolumn{2}{|c|}{$\begin{array}{l}\text { Unstandardized } \\
\text { Coefficients }\end{array}$} & \multirow{2}{*}{$\begin{array}{c}\text { Standardized } \\
\text { Coefficients } \\
\text { Beta } \\
\end{array}$} & \multirow[b]{2}{*}{$t$} & \multirow[b]{2}{*}{ Sig. } & \multicolumn{2}{|c|}{$\begin{array}{c}95,0 \% \\
\text { Confidence } \\
\text { Interval for B }\end{array}$} \\
\hline & & B & Std. Error & & & & $\begin{array}{l}\text { Lower } \\
\text { Bound }\end{array}$ & $\begin{array}{l}\text { Upper } \\
\text { Bound }\end{array}$ \\
\hline \multirow[t]{2}{*}{1} & (Constant) & 9,882 & 3,361 & & 2,940 & ,004 & 3,238 & 16,526 \\
\hline & $\begin{array}{l}\text { E.Awareness } \\
\text { E.Bihaviour } \\
\text { E.Concern } \\
\text { E.Attitude }\end{array}$ & $\begin{array}{r}, 532 \\
, 059 \\
-, 030 \\
, 072 \\
\end{array}$ & $\begin{array}{l}, 067 \\
, 023 \\
, 066 \\
, 053 \\
\end{array}$ & $\begin{array}{r}, 544 \\
, 172 \\
-, 032 \\
, 096 \\
\end{array}$ & $\begin{array}{l}7,997 \\
2,515 \\
-, 461 \\
1,355 \\
\end{array}$ & $\begin{array}{l}, 000 \\
, 013 \\
, 645 \\
, 178 \\
\end{array}$ & $\begin{array}{r}, 401 \\
, 013 \\
-, 161 \\
-, 033 \\
\end{array}$ & $\begin{array}{l}, 664 \\
, 105 \\
100 \\
, 178 \\
\end{array}$ \\
\hline
\end{tabular}

a. Dependent Variable: E.Knowledge

Pengetahuan lingkungan berpengaruh kuat terhadap kesadaran lingkungan, kemudian pada perilaku, sikap dan yang terakhir pada ketertarikan terhadap lingkungan.

\section{SIMPULAN}

Pengetahuan lingkungan dari guru sekolah dasar pada sebesar 63,20\%. Pengetahuan lingkungan berpengaruh kuat terhadap kesadaran lingkungan, perilaku dan sikap kemudian munculnya ketertarikan pada masalah lingkungan.

\section{DAFTAR PUSTAKA}

Ardoin, N. M., Biedenweg, K., \& O'Connor, K. (2015). Evaluation in Residential Environmental Education: An Applied Literature Review of Intermediary Outcomes. Applied Environmental Education and Communication, 14(1), 43-56. https://doi.org/10.1080/1533015X.2015.1013225

Bouscasse, H., Joly, I., \& Bonnel, P. (2018). How does environmental concern influence mode choice habits? A mediation analysis. Transportation Research Part D: Transport and Environment, 59, 205-222. https://doi.org/10.1016/j.trd.2018.01.007

Carmi, N., Arnon, S., \& Orion, N. (2015). Transforming Environmental Knowledge into Behavior: The Mediating Role of Environmental Emotions. Journal of Environmental Education, 46(3), 183-201. https://doi.org/10.1080/00958964.2015.1028517

Helm, S. V., Pollitt, A., Barnett, M. A., Curran, M. A., \& Craig, Z. R. (2018). Differentiating environmental concern in the context of psychological adaption to climate change. Global Environmental Change, 48(April 2017), 158-167. https://doi.org/10.1016/j.gloenvcha.2017.11.012

Karahan, E., \& Roehrig, G. (2015). Constructing Media Artifacts in a Social Constructivist Environment to Enhance Students' Environmental Awareness and Activism. Journal of Science Education and Technology, 24(1), 103-118. https://doi.org/10.1007/s10956-014-9525-5

Kokkinen, E. (2013). Measuring Environmental Awareness in the World.

Mei, N. S., Wai, C. W., \& Ahamad, R. (2016). Environmental Awareness and Behaviour Index for Malaysia. Procedia - Social and Behavioral Sciences, 222(7), 668-675. https://doi.org/10.1016/j.sbspro.2016.05.223 